The continued variation in the use of inpatient facilities across England requires further attention, particularly as it suggests that current means of resource allocation do not adequately address the marked impact of deprivation on need for mental health services.

Glover, G. R., Leese, M. \& McCrone, P. (1999) More severe mental illness is more concentrated in deprived areas. British Journal of Psychiatry, 175, 544-548.

Harrison, J., Barrow, S. \& Creed, F. (1995) Social deprivation and psychiatric admission rates among different diagnostic groups. British Journal of Psychiatry, 167, 456-462.

King's Fund (1997) edited by Sonia Johnson. London's Mental Health. The Report of the King's Fund London Commission. London: King's Fund.

Thompson, A., Shaw, M., Harrison, G., et al (2004) Problems of hospital admission for adult psychiatric illness in England: analysis of Hospital Episode Statistics data. British Journal of Psychiatry, 185, 334-34I.

J. A. Harrison Manchester Mental Health and Social Care Trust, Chorlton House, 70 Manchester Road, Manchester M2I 9UN, UK.

E-mail: Judith.Harrison@mhsc.manchester.nhs.uk

F. Creed University of Manchester, UK.

\section{Obesity and schizophrenia}

After reading less than half of 'Metabolic syndrome and schizophrenia' (Thakore, 2005) I checked the Declaration of interest and found the expected link to the pharmaceutical industry. On rereading the whole paper carefully I could not pinpoint a single statement that seemed wrong. However, the uneasy general impression remained that the author attempted to suggest that the metabolic syndrome was rather a result of schizophrenia itself and/or the associated stress than the antipsychotic drugs. Therefore, I would like to draw attention to the high probability that patients with schizophrenia were rarely overweight before the advent of neuroleptics. First, Kretschmer (1961) found that $50.3 \%$ of 5233 people with schizophrenia had a leptosome (or asthenisch) body build, for which he measured an average waist/hip ratio of 0.67 $(74.1 / 84.7 \mathrm{~cm})$ in men and $0.82(67.7 /$ $82.2 \mathrm{~cm}$ ) in women. Only $13.7 \%$ of 5233 people with schizophrenia were pyknisch, characterised by a strong development of circumference of the holes for the intestines (starke Umfangsentwicklung der Eingeweideböblen) and an average waist/hip ratio of $0.97(88.8 / 92.0 \mathrm{~cm})$ in men and $0.84(78.7 /$ $94.2 \mathrm{~cm})$ in women. The rest of the schizophrenia sample was classified as athletic, dysphasic or uncharakteristisch (not typical of any of the aforementioned). Among the 1361 people with manicdepressive illness, $64.6 \%$ were pyknisch and only $19.2 \%$ leptosome. The leptosome body build, which does not seem to indicate a risk of developing the metabolic syndrome, was thought of as typical for schizophrenia.

Second, I asked a student to classify the patients with schizophrenia on old photographs in Bleuler's textbook (1969) as probably underweight, normal weight or overweight, without letting her know the reason. She quite rightly protested that she could not carry out the task with any certainty. However, as she appears rather underweight herself and as most people tend to use themselves as a yardstick, it is unlikely that she underestimated the number of overweight patients with schizophrenia. She classified $25 \%$ ( 5 out of 20 ) as overweight, $60 \%$ (12 out of 20) as normal weight and $15 \%$ ( 3 out of 20 ) as underweight. Thus, in spite of Thakore's paper, I still think that neuroleptic drugs contribute considerably to the development of obesity and its consequences.

\section{Declaration of interest}

None.

Bleuler, M. (1969) Lehrbuch der Psychiatrie. Berlin: Springer.

Kretschmer, E. (196I) Körperbau und Charakter (23rd/ 24th edn). Berlin: Springer.

Thakore, J. H. (2005) Metabolic syndrome and schizophrenia. British Journal of Psychiatry, 186, 455-456.

C.Thiels Department of Social Sciences, University of Applied Sciences, D33615 Bielefeld, Germany. E-mail: cornelia.thiels@fh-bielefeld.de

Author's reply: In response to Professor Thiels letter, intra-abdominal fat (IAF) is critical in determining the overall risk of physical morbidity and one does not need to be overweight, or indeed obese in the conventional sense, to have an excess of IAF (Thakore, 2005). For example, patients with melancholic depression, who by definition have usually lost weight, have twice as much visceral fat as matched controls, and have higher mortality rates than the general population (Thakore et al, 1997). Hence, the patients with schizophrenia described by Kretschmer may have been underweight or of normal weight but still have carried excessive amounts of IAF, which would have increased their risk of developing a host of physical problems.

The waist/hip ratio is an indirect anthropometric measure of IAF whose value is greatly influenced by exactly where the tape measure is placed. Using a direct measure of IAF, computed tomographic scanning, we have shown in two separate studies that first-episode drug naïve nonobese patients with schizophrenia have over three times as much IAF as matched controls (Thakore et al, 2002; Ryan et al, 2004). The amounts of IAF in both of these samples were far in excess of what one would see in simple obesity, but were similar to what one might observe in patients with Cushing's syndrome. There is little doubt that most of the widely used neuroleptics (old and new) cause weight gain. Yet, using computed tomographic scanning, an acknowledged gold standard, we have shown that there is no significant increase in IAF with two commonly used atypical antipsychotics (Ryan et al, 2004). Therefore, we should be asking questions such as what has a greater physical impact on patients with schizophrenia - the illness, with all of its associated stress and poor lifestyle choices, or the medications used to control symptomatology?

\section{Declaration of interest}

J.H.T. has in the past received unrestricted educational grants from Bristol-Myers Squibb, Eli Lilly and Pfizer but is currently receiving no funding from pharmaceutical companies.

Ryan, M. C. M., Flanagan, S., Kinsella, U., et al (2004) Atypical antipsychotics and visceral fat distribution in first episode, drug-naïve patients with schizophrenia. Life Sciences, 74, 1999-2008.

Thakore, J. H. (2005) Metabolic syndrome and schizophrenia. British Journal of Psychiatry, 186, 455-456.

Thakore, J. H., Richards, P. J., Reznek, R. H., et al (1997) Increased intraabdominal fat deposition in patients with major depressive illness as measured by computed tomography. Biological Psychiatry, 4I, 1140-1142.

Thakore, J. H., Mann, J. N., Vlahoos, J., et al (2002) Increased visceral fat distribution in drug-naïve and drug-free patients with schizophrenia. International Journal of Obesity Related Metabolic Disorders, 26, |37-14|.

J. H. Thakore Neuroscience Centre, St Vincent's Hospital, Richmond Road, Fairview, Dublin 3, Ireland. E-mail: jthakore@rcsi.ie 